\title{
Manajemen Panen Kelapa Sawit (Elaeis guineensis Jacq.) di Kebun Hatantiring, Kalimantan Tengah
}

\section{Harvesting Management of Oil Palm (Elaeis guineensis Jacq.) in Hatantiring Estate, Central Kalimantan}

\author{
Antonio C Situmorang, Sofyan Zaman*, dan Ahmad Junaedi \\ Departemen Agronomi dan Hortikultura, Fakultas Pertanian, Institut Pertanian Bogor \\ (Bogor Agricultural University), Jl. Meranti, Kampus IPB Darmaga, Bogor 16680, Indonesia \\ Telp. \& Faks.62-251-8629353 e-mail agronipb@indo.net.id \\ *Penulis untuk korespondensi: sofyan_zaman@yahoo.co.id \\ Disetujui 18 Januari 2016/Published online 25 Januari 2016
}

\begin{abstract}
Internship program provides knowledge and skills in aspects of cultivating of oil palm, both technical and managerial. This internship activities were started from February 2014 to June 2014 in Hatantiring estate, Central Kalimantan. Harvesting aspects include harvest rotation, estimating production, harvesting systems, supervision of yield losses, and productivity. Observations were tested with statistical data analysis such as t-student test and analysis LSD. Based on t-student test, the delay of harvest rotation will increase the percentage of LF so that the opportunities of losses will also incrase. Result of LSD test on the first and second test showed significant results as well as the second and third test. This shows that the briefing and supervision are able to raise awareness of the employees to pressing harvest losses. Increased production can also be achieved by harvesting system that is more effective and efficient. DOL C1R2 harvesting system more effective and efficient than the DOL C1RI harvesting system because the output of harvester had increased. This contributes to the increased revenue and a reduction in number of employee.
\end{abstract}

Keywords : Hatantiring estate, management harvesting, oil palm

\begin{abstract}
ABSTRAK
Kegiatan magang memberikan ilmu dan keterampilan dalam budidaya kelapa sawit baik secara teknis maupun manajerial. Kegiatan magang dilaksanakan mulai bulan Februari hingga Juni 2014 di kebun Hatantiring, Kalimantan Tengah. Aspek pemanenan mencakup rotasi panen, taksasi produksi, sistem panen, pengawasan terhadap kehilangan hasil (losses), dan produktivitas. Pengamatan diuji dengan analisis uji $t$ student dan analisis uji LSD. Berdasarkan analisis uji $t$ diketahui bahwa rotasi panen terlambat akan menambah persentase brondolan sehingga peluang kehilangan hasil (losses) juga akan meningkat. Berdasarkan uji LSD pada pemeriksaan losses pertama dan kedua menunjukkan hasil signifikan begitu juga pada pemeriksaan kedua dan ketiga. Hal ini menunjukkan bahwa arahan dan pengawasan mampu meingkatkan kesadaran karyawan panen dalam menekan losses. Peningkatan produksi juga dapat dicapai dengan melakukan sistem panen yang lebih efektif dan efisien. Sistem panen DOL C1R2 dinilai lebih efektif dan efisien dari pada sistem panen DOL CIRI karena output pemanen mengalami peningkatan. Hal ini berpengaruh terhadap bertambahnya pendapatan karyawan dan pengurangan jumlah karyawan.
\end{abstract}

Kata kunci : Kebun Hatantiring, kelapa sawit, manajemen panen 


\section{PENDAHULUAN}

Kelapa sawit (Elaeis guineensis Jacq.) adalah tanaman tahunan penghasil minyak nabati. Menurut Pahan (2006) kelapa sawit merupakan tanaman yang paling produktif dengan produksi yang paling tinggi dibandingkan seluruh tanaman penghasil minyak nabati lainnya. Hasil olahan kelapa sawit berupa minyak sawit mentah (CPO atau Crude Palm Oil) dan minyak inti sawit (PKO atau Palm Kernel Oil).

Kelapa sawit di Indonesia terus berkembang dari tahun ke tahun. Berdasarkan data dari Direktorat Jendral Perkebunan (2013) dapat dilihat bahwa pada tahun 2012 luas areal kebun kelapa sawit adalah 9.10 juta ha dengan produksi 23.5 juta ton dan mengalami peningkatan pada tahun 2013 hingga 9.15 juta ha dengan produksi 24.4 juta ton. Peningkatan luas areal dan produksi kelapa sawit ini menunjukkan bahwa kelapa sawit merupakan tanaman komoditas perkebunan yang cukup penting di Indonesia dan masih memiliki prospek pengembangan yang cukup cerah. Ditambah lagi dengan permintaan terhadap hasil olahan kelapa sawit baik di dalam maupun di luar negeri dari tahun ke tahun terus meningkat. Hal ini merupakan peluang besar bagi Indonesia sebagai negara tropis dengan lahan yang masih relatif luas untuk memenuhi permintaan hasil olahan kelapa sawit tersebut. Peningkatan produktivitas kelapa sawit adalah cara yang tepat dilakukan untuk memenuhi permintaan hasil olahan kelapa sawit. Peningkatan produktivitas tersebut dapat dicapai dengan melakukan manajemen pemanenan yang baik.

Panen merupakan pemotongan tandan buah segar dari pohon hingga pengangkutan ke pabrik. Keberhasilan pemanenan akan menunjang pencapaian produktivitas tanaman. Sebaliknya, kegagalan akan menghambat pencapaian produktivitas tanaman kelapa sawit. Pemeliharaan yang sudah baku dan potensi tinggi tidak akan ada artinya jika pemanenan tidak optimal (PPKS, 2007).

$$
\text { Manajemen panen dilaksanakan }
$$
seoptimal mungkin dengan melakukan tindakan sebagai berikut : (a) pelaksanaan ketentuan panen seperti sistem panen, rotasi panen, kriteria matang panen dan persentase brondolan, (b) pelaksanaan angkutan panen sesegera mungkin ke pabrik dan (c) pelaksanaan pengolahan secepat mungkin (Astra Agro Niaga, 1996).

\section{BAHAN DAN METODE}

Kegiatan magang dilaksanakan di kebun Hatantiring, Kalimantan Tengah, yang dilakukan selama empat bulan dimulai dari bulan Februari 2014 hingga Mei 2014. Kegiatan magang meliputi kegiatan teknis di lapangan dan kegiatan manajerial. Pada bulan pertama dan bulan kedua, kegiatan teknis di lapangan yaitu sebagai karyawan harian lepas (KHL) dan pendamping mandor lalu pada bulan ketiga dan keempat dilakukan kegiatan manajerial yaitu sebagai asisten divisi. Kegiatan teknis di lapangan sebagai karyawan harian lepas (KHL) dilakukan pada bulan pertama dengan melakukan semua tugas lapangan yang terdiri atas pembukaan dan persiapan lahan, persiapan dan penanaman bahan tanam, pemeliharaan tanaman dan pemanenan. Selain melakukan kegiatan tersebut, penulis juga mengisi jurnal harian yang diketahui pembimbing lapangan dan mencatat prestasi kerja yang diperoleh mahasiswa dan karyawan setiap kali mengikuti kegiatan yang akan dibandingkan dengan norma kerja yang berlaku di perusahaan tempat magang.

Pada bulan kedua, dilakukan kegiatan sebagai pendamping mandor. Kegiatan yang dilakukan menyangkut kegiatan manajerial yang bertugas membuat perencanaan dari setiap kegiatan yang akan dilakukan, menentukan jumlah karyawan yang diperlukan beserta keperluan biaya operasional dari setiap kegiatan, mengawasi karyawan harian di setiap kegiatan, membuat analisis pekerjaan, mengawasi karyawan yang bekerja dan membantu pembuatan laporan harian, bulanan, mingguan, dan bulanan mandor. Memasuki bulan ketiga dan keempat, kegiatan manajerial akan dilakukan sebagai asisten divisi yang bertugas membantu untuk menyusun rencana kerja dan anggaran perusahaan (RKAP), mempelajari kegiatan manajerial di tingkat divisi kebun, pengelolaan, pengawasan karyawan, membuat jurnal harian, dan membantu pembuatan laporan asisten divisi.

Pengumpulan data pada kegiatan magang ini dilakukan dengan menggunakan metode langsung (data primer) dan metode tidak langsung (data sekunder). Pengumpulan data primer dilakukan melalui pengamatan langsung pada saat pelaksanaan magang di lapangan. Berikut pengamatan data primer: a) rotasi panen (pengamatan rotasi panen dilakukan dengan cara membandingkan persentase bobot brondolan pada saat rotasi panen normal dan rotasi panen terlambat, (pengamatan dilakukan pada blok yang sama), b) taksasi produksi (pengamatan taksasi 
produksi dilakukan dengan cara membandingkan hasil taksasi dan produksi yang sebenarnya. Jumlah pokok sampel yang ditetapkan adalah 100 pokok secara zigzag kemudian menentukan persentase kermatangan buah dengan cara menghitung buah masak disetiap pokok sampel yang telah ditentukan), c) kehilangan hasil (losses) (pengamatan kehilangan hasil (losses) dilakukan dengan mengamati brondolan yang tidak terkutip di dalam blok. Pengamatan dilakukan dengan tiga kali pemeriksaan. Pemeriksaan pertama dilakukan tanpa ada arahan kepada karyawan panen, pemeriksaan kedua dilakukan dengan memberikan arahan kepada karyawan panen saat apel pagi, dan pemeriksaan ketiga dilakukan dengan memberikan arahan dan pemberian hadiah kepada karyawan yang mendapatkan persentasi losses terendah), d) sistem panen (sistem panen yang diterapkan di kebun Hatantiring adalah sistem panen Division Of Labour (DOL) dengan dua metode yaitu DOL C1R1 (Cutter dan Picker) dan DOL C1R2 (Cutter, Picker dan Frondstecker). Pengamatan yang dilakukan adalah membandingkan sistem panen yang lebih efektif dan efisen pada sistem panen DOL C1R1 dan DOL C1R2), e) produktivitas (pengamatan produktivitas dilakukan dengan cara menghitung jumlah produksi pada tahun tanam yang berbeda. Tahun tanam yang akan diuji adalah tahun tanam 1998 dan tahun tanam 2007).

Data sekunder diperoleh dari kebun, berupa arsip perusahaan meliputi: (1) data kondisi kebun antara lain: areal, jenis lahan, topografi lahan, data curah hujan sepuluh tahun terakhir, dan data premi panen (2) data kondisi tanaman antara lain asal bahan tanaman, populasi tanaman, umur tanaman, produksi dan produktifitas lima tahun terakhir, (3) standar kebun meliputi: penanaman, pemeliharaan, pemanenan, dan tenaga kerja, (4) organisasi dan manajemen seperti: srtuktur organisasi, jumlah dan status karyawan, dan (5) sarana atau prasarana kebun.

\section{HASIL DAN PEMBAHASAN}

\section{Manajamen Panen}

Manajemen adalah proses
mengkoordinasikan aktivitas-aktivitas kerja
sehingga dapat selesai secara efektif dan efisien
dengan dan melalui orang lain. Menurut Risza
(2010) manfaat manajemen adalah mengetahui
proses manajemen yang perlu ditempuh agar
tujuan organisasi perusahaan dapat tercapai dan

mengetahui kegunaan unsur-unsur manajemen yang diperlukan untuk mencapai tujuan organisasi.

Proses manajemen terdiri a t a s merencanakan (planning), mengorganisasikan (organizing), memimpin (leading), dan mengawasi (controlling) (Robbins dan Coulter, 2005). Perencanaan panen mencakup kegiatan taksasi produksi yang terdiri atas penetapan pokok sampel dan AKP (angka kerapatan panen). AKP diperoleh dengan cara menghitung jumlah buah matang pada pokok sampel kemudian dikali dengan total pokok produksi pada blok tersebut. Berdasarkan taksasi yang diperoleh dapat diketahui jumlah pemanen dan jumlah armada yang dibutuhkan sehingga pelaksanaan panen dapat berjalan dengan baik, namun di kebun Hatantiring secara khusus di Divisi III jumlah tenaga kerja belum memenuhi standar.

Berdasarkan standar perusahaan bahwa jumlah tenaga pemanen ideal dalam satu divisi adalah 80 orang per hari, dapat dilihat pada perhitungan indeks tenaga kerja (ITK) berikut :

Luas areal panen : 1154 ha

Standar ketetapan perusahaan : 16

a. Kebutuhan tenaga pemanen

$$
\begin{aligned}
& =\frac{\text { luasarealTM }}{16} \\
& =\frac{1154}{16} \\
& =72
\end{aligned}
$$

b. Cadangan pemanen $=72 \times 10 \%=8$

c. Jumlah tenaga pemanen $=$ kebutuhan tenaga pemanen + cadangan pemanenan $=72+8$ $=80$ Pemanen per hari

Pada kenyataannya, jumlah tenaga pemanen di Divisi III adalah 66 orang. Hal ini menyebabkan seksi panen yang harus diselesaikan dalam satu hari tidak selesai sehingga menyebabkan rotasi panen terlambat. Di Divisi III, panen dilakukan pada hari libur dan hari minggu untuk mengejar rotasi panen yang terlambat. Selain itu, perusahaan juga mencoba mengubah sistem panen agar dapat menghemat tenaga kerja dalam pelaksanaan panen.

Pengorganisasian mencakup struktur organisasi afdeling, penetapan sistem panen yang terdiri atas pemotong TBS (cuter) dan pembrondol (picker), pembagian pemanen menjadi tiga kemandoran dan pembagian hanca panen. Kepemimpinan mencakup pelaksanaan panen yakni memastikan adanya alat pelindung diri (APD), kelengkapan alat panen dan bertanggung jawab atas seluruh kegiatan teknis di 
divisi. Pengawasan mencakup kualitas buah yang dipanen, tangkai tandan dipotong pendek (long stack), brodolan dikutip, pelepah dipotong dan disusun, dan tidak ada buah yang tertinggal di hancak maupun TPH.

\section{Rotasi Panen}

Rotasi panen adalah selang waktu yang dibutuhkan dari panen di blok pertama sampai panen kembali ke blok tersebut. Rotasi panen yang terlalu cepat (rendah) akan mengakibatkan pemanen cenderung memotong buah under ripe (agak mentah) dan unripe (mentah) sedangkan rotasi panen yang terlambat (tinggi) dapat menyebabkan buah overipe (terlalu masak) yang akan menjadi empty bunch (buah busuk).

Di Divisi III terjadi rotasi panen tinggi yaitu mencapai rotasi 20 hari. Hal ini terjadi karena kondisi buah pada panen puncak (peak crop), curah hujan tinggi, dan kekurangan tenaga kerja (berdasarkan perhitungan ITK). Kondisi buah peak crop menyebabkan buah banyak sehingga pelaksanaan panen menjadi lambat ditambah kondisi tenaga kerja yang masih kurang. Curah hujan yang tinggi juga menyebabkan aktivitas panen terganggu, karena ada blok-blok tertentu yang tergenang sehingga tidak bisa dipanen. Hal ini menyebabkan seksi panen satu hari tidak selesai maka rotasi panen menjadi tinggi. Berdasarkan rotasi panen tinggi tersebut dilakukan pengamatan perentase bobot brondolan pada rotasi panen yang berbeda. Rotasi panen yang diamati adalah rotasi panen 10 hari dan rotasi panen 20 hari. Pengambilan data dilakukan dengan cara menghitung bobot brondolan yang telah dikumpulkan di TPH menggunakan tongkat yang telah dikalibrasi. Berdasarkan Tabel 1 diketahui bahwa pengamatan rotasi panen 10 hari dilakukan pada tanggal 3-9 Maret 2014 masing- masing pada field S001, S002, R001, R002, V001, V002, dan V003, sedangkan untuk rotasi panen 20 hari pada Tabel 2 pengamatan dilakukan pada tanggal 21-27 Mei 2014 dengan masing-masing field S001, S002, R001, R002, V001, V002, dan V003. Hal ini menunjukkan bahwa pengamatan dilakukan sebanyak tujuh kali pada waktu yang berbeda, namun blok yang sama.

Berdasarkan analisis uji t pada Tabel 3 perbandingan bobot brondolan rotasi panen 10 hari dan rotasi panen 20 hari menunjukkan hasil yang sangat berbeda nyata artinya persentase bobot brondolan meningkat pada rotasi panen tinggi. Pahan (2006) juga menyatakan bahwa jumlah brondolan akan meningkat sesuai dengan rotasi panen yang semakin tinggi.

Tabel 1. Pengamatan bobot brondolan pada rotasi panen 10 hari

\begin{tabular}{llccrc}
\hline Tanggal & Field & Luas field & Panen (ha) & Kebun (ha) & $\mathrm{kg} \mathrm{ha}^{-1}$ \\
\hline $03 / 03 / 2014$ & S001 & 63 & 40 & 1506 & 38 \\
$04 / 03 / 2014$ & S002 & 60 & 60 & 2413 & 40 \\
$05 / 03 / 2014$ & R001 & 18 & 8 & 394 & 49 \\
$06 / 03 / 2014$ & R002 & 101 & 66 & 3831 & 58 \\
$07 / 03 / 2014$ & V001 & 75 & 37 & 1892 & 51 \\
$08 / 03 / 2014$ & V002 & 69 & 39 & 1839 & 47 \\
$09 / 03 / 2014$ & V003 & 72 & 66 & 2827 & 43 \\
\hline
\end{tabular}

Tabel 2. Pengamatan bobot brondolan pada rotasi panen 20 hari

\begin{tabular}{llcccc}
\hline Tanggal & Field & Luas field & Panen (ha) & Kebun (ha) & $\mathrm{kg} \mathrm{ha}^{-{ }^{-1}}$ \\
\hline $21 / 05 / 2014$ & S001 & 63 & 42 & 15063 & 359 \\
$22 / 05 / 2014$ & S002 & 60 & 50 & 15708 & 314 \\
$23 / 05 / 2014$ & R001 & 18 & 7 & 2091 & 299 \\
$24 / 05 / 2014$ & R002 & 101 & 33 & 11364 & 344 \\
$25 / 05 / 2014$ & V001 & 75 & 40 & 13265 & 332 \\
$26 / 05 / 2014$ & V002 & 69 & 34 & 12304 & 362 \\
$27 / 05 / 2014$ & V003 & 72 & 25 & 9051 & 362 \\
\hline
\end{tabular}


Tabel 3. Perbandingan bobot brondolan pada dua rotasi panen

\begin{tabular}{|c|c|c|c|c|}
\hline \multirow{2}{*}{ Pengamatan } & \multicolumn{2}{|c|}{ Rotasi panen $\left(\mathrm{kg} \mathrm{ha}^{-1}\right)$} & \multirow{2}{*}{ t-hitung } & \multirow{2}{*}{$\operatorname{Pr}>t$} \\
\hline & 10 Hari & 20 Hari & & \\
\hline I & 38 & 359 & & \\
\hline II & 40 & 314 & & \\
\hline III & 49 & 299 & & \\
\hline IV & 58 & 344 & & \\
\hline $\mathrm{V}$ & 51 & 332 & & \\
\hline VI & 47 & 362 & & \\
\hline VII & 43 & 367 & & \\
\hline Rata-rata & 46.57 & 338.9 & -29.79 & $0.000 * *$ \\
\hline
\end{tabular}

Keterangan : ** = berbeda sangat nyata pada uji t

Rotasi panen tinggi menyebabkan banyaknya buah busuk dan losses. Di kebun Hatantiring, panen dilaksanakan pada hari minggu dan hari libur. Hal ini merupakan salah satu cara yang dilakukan untuk mempercepat rotasi panen.
Penambahan premi pada saat hari minggu dan hari libur adalah salah satu cara perusahaan untuk mendorong motivasi karyawan sehingga pelaksanaan panen dapat berjalan dengan maksimal.

Tabel 4. Produksi Berdasarkan Taksasi dan Realisasi

\begin{tabular}{lcccccccrrrr}
\hline $\begin{array}{l}\text { Blok Luas } \\
\text { (ha) }\end{array}$ & $\begin{array}{c}\text { Pokok } \\
\text { produksi }\end{array}$ & $\begin{array}{c}\text { Pokok } \\
\text { sampel }\end{array}$ & $\begin{array}{c}\text { Pokok } \\
\text { Sampel } \\
(\%)\end{array}$ & $\begin{array}{c}\text { BJR } \\
\text { Matang } \\
(\%)\end{array}$ & $\begin{array}{c}\text { Buah } \\
\text { Janjang }\end{array}$ & $\begin{array}{c}\text { Taksasi } \\
(\mathrm{kg})\end{array}$ & $\begin{array}{c}\text { Realisasi } \\
(\mathrm{kg})\end{array}$ & $\begin{array}{c}\text { Selisih } \\
\text { produksi }\end{array}$ & $\begin{array}{c}\text { Selisih } \\
\text { Produksi } \\
(\%)\end{array}$ \\
\hline V02 & 69 & 9246 & 100 & 1.08 & 10.15 & 32 & 2959 & 30031 & 42420 & 12389 & 4125 \\
U02 & 30 & 4050 & 100 & 2.47 & 10.36 & 32 & 1296 & 13427 & 12850 & -577 & -4.29 \\
S02 & 50 & 6700 & 100 & 1.49 & 9.17 & 35 & 2345 & 21504 & 28066 & 6562 & 30.52 \\
S01 & 40 & 5200 & 100 & 1.92 & 8.98 & 39 & 2028 & 18211 & 20980 & 2769 & 15.20 \\
V03 & 30 & 4020 & 100 & 2.49 & 10.15 & 37 & 1487 & 15097 & 14660 & -437 & -2.90 \\
U03 & 30 & 4020 & 100 & 2.49 & 16.30 & 31 & 1246 & 20313 & 20908 & 595 & 2.93 \\
U04 & 51 & 6630 & 100 & 1.51 & 19.50 & 27 & 1790 & 34907 & 30064 & -4843 & -13.87 \\
U05 & 30 & 4020 & 100 & 2.49 & 19.18 & 25 & 1005 & 19276 & 18830 & -446 & -2.31 \\
U06 & 52 & 6988 & 100 & 1.43 & 17.89 & 31 & 2166 & 38755 & 36620 & -2135 & -5.51 \\
U07 & 46 & 6630 & 100 & 1.51 & 16.04 & 23 & 1525 & 24459 & 34220 & 9761 & 39.91 \\
\hline \multicolumn{2}{l}{ Rata-rata } \\
\hline
\end{tabular}

\section{Taksasi produksi}

Taksasi produksi merupkan perhitungan yang dilakukan untuk mengetahui estimasi produksi esok harinya. Kegunaan taksasi produsi adalah untuk mengetahui jumlah tenaga kerja dan jumlah armada yang dibutuhkan. Taksasi produksi dilakukan dengan mengambil sampel 100 pokok pada setiap blok secara zigzag kemudian menentukan persentase kematangan buah dengan menghitung jumlah buah matang pada setiap pokok sampel. Persentase kematangan buah tersebut akan dikali dengan bobot janjang

rata-rata (BJR) sehingga diperoleh estimasi tonase produksi. Perhitungan taksasi akan diuji keakuratannya dengan menghitung produksi aktual kebun dengan standar toleransi kurang lebih 5\%.

Di Divisi III, penentuan taksasi produksi tergolong belum akurat, berdasarkan data pada Tabel 4 yang menunjukkan bahwa hasil taksasi produksi $10.09 \%$. Hal ini disebabkan karena adanya penggabungan beberapa blok dengan tahun tanam yang berbeda menjadi satu field. Penggabungan beberapa blok tersebut menjadikan pemutihan pada field tersebut dengan menentukan tahun tanam yang lebih dominan. Pemutihan pada field ini berpengaruh terhadap bobot janjang ratarata (BJR) yang nantinya akan mempengaruhi taksasi produksi.

Penentuan sampel yang belum mewakili kondisi blok secara menyeluruh (terlalu sedikit) juga merupakan salah satu faktor penyebab taksasi produksi kurang akurat. Pada Tabel 5 pengaruh persentase pokok sampel terhadap persentase selisih produksi menunjukkan hasil berbeda nyata. Hal ini menunjukkan bahwa pokok sampel yang diambil mempengaruhi persentase selisih produksi. Berdasarkan uji t pada Tabel 5 tersebut dapat disimpulkan bahwa semakin tinggi persentase pokok sampel maka taksasi produksi yang diperoleh akan semakin akurat. 
Tabel 5. Pengaruh persentase pokok sampel terhadap persentase selisih produksi

\begin{tabular}{|c|c|c|c|c|}
\hline \multirow[t]{2}{*}{ Variabel } & \multicolumn{2}{|c|}{$\begin{array}{c}\text { Persentase pokok } \\
\text { sampel }(\%)\end{array}$} & \multirow{2}{*}{$\begin{array}{c}\mathrm{t}- \\
\text { hitung }\end{array}$} & \multirow[t]{2}{*}{$\operatorname{Pr}>t$} \\
\hline & $<2$ & $\geq 2$ & & \\
\hline $\begin{array}{l}\text { Selisih } \\
\text { produksi } \\
(\%)\end{array}$ & 25.4 & 3.108 & 3.76 & $0.013 *$ \\
\hline
\end{tabular}

Keterangan : * = berbeda nyata pada uji t

\section{Kehilangan hasil (Losses)}

Kehilangan hasil (losses) merupakan kerugian produksi. Menurut pahan (2006) produksi yang maksimal hanya dapat dicapai jika kerugian (losses) produksi minimal. Sumbersumber kerugian produksi di lapangan ialah potong buah mentah, buah masak tinggal di pokok (tidak dipanen), brondolan tidak dikutip, buah atau brodolan dicuri, serta buah di TPH tidak terangkut ke PKS. Kegiatan menurunkan kerugian produksi perlu dilakukan dengan memberikan arahan dan melakukan pengawasan pada saat apel pagi maupun pada saat pelaksanaan panen. Arahan yang diberikan akan diawasi dengan melakukan pemeriksaan pada hancak yang telah dipanen dengan cara menentukan persentase brondolan yang tidak dikutip. Persentase brondolan tidak terkutip dapat diperoleh dengan membandingkan jumlah brondolan yang tidak dikutip dengan jumlah pokok yang dipanen.

Berdasarkan hasil uji normalitas pada dapat dilihat bahwa nilai uji hedonik kehilangan hasil (losses) memiliki nilai $\mathrm{p} \geq 0.05$ sehingga data tersebut dapat dikatakan normal dan data tersebar normal, selanjutnya dapat dilakukan uji beda ANOVA pada Tabel 7.

Tabel 7. Uji beda Anova kehilangan hasil (losse)

\begin{tabular}{llllll}
\hline Source & Sum square & Df & Mean square & F & Sig \\
\hline Between groups & 1.14 & 2 & 0.57 & 19.05 & 0.00 \\
Within groups & 2.97 & 99 & 0.03 & & \\
\hline Total & 4.11 & 101 & & & \\
\hline
\end{tabular}

Pada kolom Signifikan Tabel 7 dapat dilihat bahwa nilai $\mathrm{p}<0.05$ yang berarti data dapat dinyatakan signifikan. Berdasarkan hasil yang signifikan dapat dilakukan uji lanjut LSD untuk masing-masing pemeriksaan yang dilakukan.

Tabel 8. Uji lanjut LSD kehilangan hasil (losses)

\begin{tabular}{ccrrrrr}
\hline $\begin{array}{c}(\mathrm{I}) \\
\text { Pemeriksaan }\end{array}$ & $\begin{array}{c}(\mathrm{j}) \\
\text { Pemeriksaan }\end{array}$ & Mean & $\begin{array}{r}\text { Difference } \\
(\mathrm{I}-\mathrm{J})\end{array}$ & Std. Error & Sig. & 95\% Confidence \\
\hline 1 & 2 & 0.19 & 0.04 & 0.00 & 0.11 & 0.28 \\
& 3 & 0.25 & 0.04 & 0.00 & 0.16 & 0.33 \\
2 & 1 & -0.19 & 0.04 & 0.00 & -0.28 & -0.11 \\
& 3 & 0.05 & 0.04 & 0.21 & -0.03 & 0.14 \\
& 1 & -0.25 & 0.04 & 0.00 & -0.33 & -0.16 \\
& 2 & -0.05 & 0.04 & 0.21 & -0.14 & 0.03 \\
\hline
\end{tabular}

Pada uji lanjut LSD pada Tabel 8 dapat dilihat bahwa nilai p pada pemeriksaan 1 dan 2 dinyatakan signifikan $(\mathrm{p}<0.05)$ begitu juga pada pemeriksaan 1 dan 3 menunjukkan hasil yang signifikan juga, sementara pada pemeriksaan 2 dan 3 menunjukkan hasil yang tidak siginifikan dinyatakan dalam nilai $p>0.05 \quad(0.21)$. Berdasarkan data diatas dapat disimpulkan bahwa pemeriksaan 1 memiliki perbedaan yang signifikan terhadap pemeriksaan 2 dan 3 , namun antara pemeriksaan 2 dan 3 tidak memiliki perbedaan yang signifikan.

Tabel 9. Deskripsi rata-rata statistik pada Uji LSD

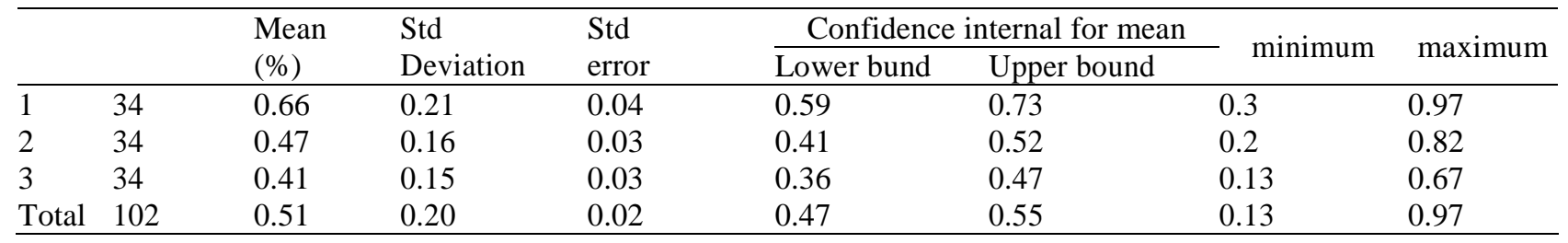


Berdasarkan data pada Tabel 9 menunjukkan bahwa rata-rata losses yang dihasilkan pada setiap pemeriksaan berbeda. Pada pemeriksaan 1 menunjukkan persentase losses sebanyak $0.66 \%$ dan mengalami penurunan yang signifikan hingga $0.47 \%$ pada pemeriksaan 2 . Hal ini menunjukkan bahwa arahan yang diberikan mampu meningkatkan kesadaran karyawan dalam menekan losses, kemudian mengalami penurunan lagi pada pemeriksaan 3 hingga mencapai $0.41 \%$ artinya pemberian arahan dan reward kepada karyawan mampu mempengaruhi karyawan dalam menekan losses akan tetapi tidak signifikan.

\section{Sistem panen C1R1 dan C1R2}

Sistem panen yang diterapkan di kebun Hatantiring adalah sistem panen DOL C1R1 dan DOL C1R2. DOL C1R1 terdiri atas 2 orang karyawan panen dalam satu tim (Cutter dan Picker), sedangkan pada sistem panen DOL C1R2 terdiri atas 3 orang karyawan panen dalam satu tim (Cutter, Frondstecker dan Picker). Pada sistem panen DOL C1R1 Cutter bertugas memotong TBS, menyusun pelepah, memotong gagang dan menyusun TBS di TPH, sedangkan Picker bertugas mengutip dan menyusun brondolan di TPH. Pada sistem panen DOL C1R2 Cutter bertugas memotong TBS dan memotong gagang panjang, Picker bertugas membrondol dan menyusun di TPH dan Frondsetcker bertugas menyusun pelepah lalu membawa TBS yang telah dipotong oleh pemanen dan menyusun di TPH. Sistem panen DOL C1R2 merupakan sistem panen baru yang diterapkan oleh Managemen perusahaan untuk menambah produksi sekaligus mampu mengatasi masalah kekurangan tenaga kerja. Pengamatan dilakukan terhadap sistem panen DOL C1R1 dan DOL C1R2 dengan parameter yang akan di uji adalah output pemanen dan luasan ha panen (ha cover).
Tabel 10. Perbandingan output dan ha cover pemanen pada sistem panen yang berbeda

\begin{tabular}{|c|c|c|c|c|}
\hline \multirow{2}{*}{ Variabel } & \multicolumn{2}{|c|}{ Sistem panen } & \multirow{2}{*}{$\begin{array}{l}\mathrm{t}- \\
\text { aitung }\end{array}$} & \multirow{2}{*}{$\operatorname{Pr}>t$} \\
\hline & C1R1 & C1R2 & & \\
\hline Output pemanen $(\mathrm{kg})$ & 1468 & 1801 & -4.80 & $0.001 * *$ \\
\hline ha cover (ha) & 3.50 & 6.03 & -4.38 & $0.001 * *$ \\
\hline
\end{tabular}

Berdasarkan analisis uji t output dan $h a$ cover pemanen pada Tabel 10 menunjukkan hasil yang sangat berbeda nyata. Output dan ha cover pemanen pada sistem panen DOL C1R2 mendapatkan hasil yang lebih tinggi dari pada sistem panen DOL C1R1. Peningkatan Output dan ha cover Pemanen tersebut terjadi karena sistem panen C1R2 lebih terstruktur dari pada sistem panen C1R1. Pada sistem panen C1R2 ada penambahan karyawan dalam satu tim yaitu frondstecker yang bekerja membantu cutter dalam mengangkut buah ke TPH. Pembagian tugas yang dilakukan pada cutter, picker, dan frondstecker mampu memaksimalkan waktu dalam pelaksanaan panen karena pada sistem panen C1R1, cutter mengalami kehilangan waktu cukup banyak saat membawa buah ke TPH sehingga buah yang dihasilkan tidak terlalu banyak.

Penambahan frondstecker pada sistem panen DOL C1R2 dinilai sangat efektif karena cutter dapat bekerja memotong buah dengan leluasa tanpa terbebani untuk membawa buah ke TPH dan berdasarkan analisis yang dilakukan bahwa penambahan frondstecker tersebut sangat berpengaruh terhadap peningkatan output dan ha cover karyawan panen. Output pemanen yang tinggi akan menambah premi karyawan sehingga pendapatan karyawan akan meningkat juga. Begitu juga dengan peningkatan ha cover yang mampu menghemat tenaga kerja. Pengurangan tenaga kerja tersebut dapat membantu perusahaan dalam menyelesaikan permasalahan kekurangan tenaga kerja.

Dapat dilihat dengan perhitungan berikut :

Luas panen C1R1

$$
\begin{aligned}
& =\mathrm{Ha} \text { cover Cutter } \mathrm{x} \text { jumlah Cutter }(\mathrm{HK}) \\
& =3.50 \times 36 \mathrm{HK}=126 \mathrm{Ha}
\end{aligned}
$$

Jumlah Pemanen (cutter) C1R2 yang dibutuhkan :

$=$ Luas panen $\mathrm{C} 1 \mathrm{R} 1 / 6.03$

$=126 \mathrm{Ha} / 6.03=21 \mathrm{HK}$

Maka, jumlah karyawan C1R2 total adalah

$=21$ (cutter) x 3 (cutter, picker dan frondstecker)

$=63 \mathrm{HK}$ 
Berdasarkan perhitungan dapat dilihat bahwa kebutuhan tenaga kerja untuk sistem panen DOL C1R2 adalah $63 \mathrm{HK}$ yang terdiri atas 21 cutter, 21 picker, dan 21 frondstecker berbeda dengan sistem panen DOL C1R1 dengan total karywan panen sebanyak $72 \mathrm{HK}$ yang terdiri atas 36 cutter, 36 picker. Penetapan sistem panen DOL C1R2 dinilai lebih efektif dan efesien dari pada sistem panen DOL C1R1 karena mampu meningkatkan pendapatan karyawan dan menghemat tenaga kerja sebanyak 9 HK sehingga dapat mengatasi masalah kekurangan tenaga kerja di kebun Hatantiring.

\section{Produktivitas}

Produktivitas merupakan perbandingan antara produksi dan luas panen. Berdasarkan produktivitas dapat diketahui keberhasilan suatu perusahaan, semakin tinggi produktivitas yang dihasilkan maka dapat dikatakan perusahaan tersebut berhasil. Di kebun Hatantiring terdapat pokok dengan tahun tanam yang berbeda yaitu 1997, 1998, 1999, 2000, 2004, 2005, 2006 dan 2007. Berdasarkan perbedaan tahun tanam tersebut dilakukan pengamatan terhadap produktivitas dan jumlah TBS yang dihasilkan.
Pengamatan dilakukan pada dua tahun tanam yaitu tahun tanam 2007 dan 1998.

Tabel 11 menunjukkan bahwa pokok tahun tanam 2007 memiliki BJR yang lebih rendah dari pada BJR pokok tahun tanam 1998, berbanding terbalik pada jumlah TBS yang dihasilkan yaitu pada pokok tahun tanam 2007 menghasilkan jumlah TBS lebih tinggi dari pada pokok tahun tanam 1998. Berdasarkan analisis uji $\mathrm{t}$ pada Tabel 12 juga menunjukkan hasil yang sangat berbeda nyata pada BJR dan jumlah TBS / ha dengan tahun tanam berbeda. Hal ini menunjukkan bahwa peningkatan BJR dan julmah TBS berpengaruh terhadap umur tanaman kelapa sawit. Semakin tua pokok kelapa sawit maka semakin tinggi pula BJR yang dihasilkan tetapi jumlah TBSnya akan menurun.

Begitu pula pada peningkatan produktivitas. Menurut Setyamidjaja (2006) bahwa usia tanaman mempengaruhi produktivitas kebun. Berdasarkan analisis uji t pada Tabel 12 menunjukkan hasil berbeda nyata pada produktivitas kelapa sawit, artinya pokok kelapa sawit dengan dengan tahun tanam 1998 yang berusia 16 Tahun menghasilkan produktivitas $672.4 \mathrm{~kg} \mathrm{ha}^{-1}$ berbeda dengan kelapa sawit tahun tanam 2007 yang berusia 7 Tahun menghasilkan produktivitas $548.5 \mathrm{~kg} \mathrm{ha}^{-1}$.

Tabel 11. Produksi pada tahun tanam 2007 dan 1998

\begin{tabular}{llrrrrrrr}
\hline Field & $\begin{array}{l}\text { Tahun } \\
\text { Tanam }\end{array}$ & $\begin{array}{r}\text { Luas } \\
\text { (Ha) }\end{array}$ & $\begin{array}{c}\text { Pokok } \\
\text { produksi }\end{array}$ & \multicolumn{1}{c}{ BJR } & TBS & TBS / ha & $\begin{array}{r}\text { Produksi } \\
(\mathrm{kg})\end{array}$ & $\begin{array}{r}\text { Produktivitas } \\
\left(\mathrm{kg} \mathrm{ha}^{-1}\right)\end{array}$ \\
\hline V002 & 2007 & 69 & 9246 & 10.15 & 3513 & 51 & 42420 & 614.78 \\
U001 & 2007 & 30 & 4050 & 10.36 & 1499 & 50 & 12850 & 428.33 \\
S002 & 2007 & 50 & 6700 & 9.17 & 2345 & 47 & 28066 & 561.32 \\
S001 & 2007 & 40 & 5200 & 8.98 & 1976 & 49 & 25980 & 649.5 \\
Y002 & 2007 & 30 & 4020 & 10.15 & 1523 & 51 & 14660 & 438.67 \\
Rata- & & & & 9.76 & 2172.2 & 49.6 & 24795.2 & 548.52 \\
U003 & 1998 & 30 & 4020 & 16.30 & 1085 & 36 & 20908 & 696.93 \\
U004 & 1998 & 51 & 6630 & 19.50 & 1856 & 36 & 30064 & 589.49 \\
U004 & 1998 & 30 & 4020 & 19.18 & 1005 & 34 & 18830 & 627.67 \\
U003 & 1998 & 52 & 6988 & 17.89 & 2096 & 40 & 36620 & 704.23 \\
U004 & 1998 & 46 & 6630 & 16.04 & 1591 & 35 & 34220 & 743.91 \\
Rata- & 1998 & & & 17.78 & 1526.6 & 36.2 & 28128.4 & 672.446 \\
\hline
\end{tabular}

Tabel 12. Perbandingan TBS per ha dan produktivitas pada tahun tanam berbeda

\begin{tabular}{lrccc}
\hline \multirow{2}{*}{ Variabel } & \multicolumn{3}{c}{ Tahun tanam } & \multicolumn{2}{c}{ t-hitung } & \multirow{2}{*}{$\operatorname{Pr}>\mathrm{t}$} \\
\cline { 2 - 4 } & 2007 & 1998 & -10.45 & $0.00^{* *}$ \\
BJR & 9.7 & 17.7 & 10.59 & $0.00^{* *}$ \\
TBS / ha & 49.6 & 36.2 & -2.52 & $0.04^{*}$ \\
\hline Produktvitas (kg/ha) & 548.5 & 672.4 &
\end{tabular}

Keterangan : ${ }^{*}=$ sangat berbeda nyata pada uji $\mathrm{t} ; *$ = berbeda nyata pada uji $\mathrm{t}$ 


\section{KESIMPULAN}

Persiapan panen yang meliputi penentuan taksasi produksi masih tergolong kurang akurat. Hal ini menyebabkan penentuan jumlah armada pengangkutan buah dan jumlah tenaga kerja tidak seimbang. Taksasi produksi yang tidak akurat disebabkan karena adanya penggabungan beberapa blok dengan tahun tanam yang berbeda menjadi satu field. Penggabungan beberapa blok menjadikan pemutihan pada field tersebut dengan menentukan tahun tanam yang lebih dominan sehingga BJR pada blok tersebut tidak merata selain itu pokok sampel yang digunakan juga kurang mewakili seluruh blok.

Pada organisasi dan pelaksanaan panen dilakukan pembagian sistem panen DOL C1R1 dan DOL C1R2. Berdasarkan data yang didapatkan bahwa sistem panen DOL C1R2 lebih efektif dan efesien karena penambahan ha cover yang dihasilkan menguntungkan perusahaan dalam penghematan tenaga kerja sehingga permasalahan kurangnya tenaga kerja dapat teratasi. Penambahan output pemanen juga menguntungkan karyawan karena menambah premi karyawan setiap harinya.

Di kebun Hatantiring terjadi rotasi panen yang terlambat sehingga menyebabkan peningkatan persentase brondolan. Peningkatan persentase brondolan tersebut menyebabkan peluang losses semakin tinggi maka diperlukan pengawasan yang baik. Pengawasan panen di kebun Hatantiring secara umum sudah berjalan dengan baik. Pemberian arahan dan pengecekan hancak mampu meningkatkan kesadaran untuk menekan losses. Di kebun Hatantiring, terdapat tahun tanam yang berbeda-beda. Berdasarkan data yang didapat bahwa tahun tanam mempengaruhi
BJR, jumlah TBS dan produktivitas kelapa sawit. Pada pokok tahun tanam tua mengalami peningkatan BJR dan penurunan TBS berbanding terbalik pada pokok tahun tanam muda yang menghasilkan BJR rendah dengan jumlah TBS banyak.

\section{DAFTAR PUSTAKA}

Astra Agro Niaga. 1996. Pedoman Brevet Dasar II. Tanaman Kelapa Sawit. Jakarta (ID): Astra Agro Niaga. Ditjenbun. 2013. Perkembangan luas areal perkebunan 2009-2013 [Internet]. [diunduh 2013 Nov 11]. Tersedia pada: http://ditjenbun. deptan.go.id/tinymcpuk/gambar/file/Luas _Areal_Estimasi_2013.pdf.

Pahan, I. 2006. Kelapa Sawit: Manajemen Agribisnis dari Hulu hingga Hilir. Cetakan I. Jakarta (ID): Penebar Swadaya.

[PPKS] Pusat Penelitian Kelapa Sawit. 2007. Budidaya Kelapa Sawit. Medan (ID): Pusat Penelitian Kelapa Sawit.

Robbins, S.P, Coulter, M. 2005. Manajemen. Slamet H, penerjemah. Jakarta (ID): PT Indeks. Terjemah dari: Management. Ed ke-8.

Setyamidjaja, D. 2006. Seni Budi Daya, Kelapa Sawit. Yogyakarta (ID): Kanisius.

Risza, S. 2010. Masa Depan Perkebunan Kelapa Sawit Indonesia. Yogyakarta (ID): Kanisius. 